\title{
Modeling Action Research for Pre-Service Teachers as Part of a Primary Maths Method Class
}

\author{
Todd Milford, Lyndal Hellaby, Rebekah Strang \\ School of Education and Professional Studies, Griffith University, Brisbane, Australia \\ Email: t.milford@griffith.edu.au
}

Received October $8^{\text {th }}$, 2013; revised November $8^{\text {th }}$, 2013; accepted November $15^{\text {th }}, 2013$

\begin{abstract}
Copyright (C) 2013 Todd Milford et al. This is an open access article distributed under the Creative Commons Attribution License, which permits unrestricted use, distribution, and reproduction in any medium, provided the original work is properly cited. In accordance of the Creative Commons Attribution License all Copyrights (C) 2013 are reserved for SCIRP and the owner of the intellectual property Todd Milford et al. All Copyright (C) 2013 are guarded by law and by SCIRP as a guardian.
\end{abstract}

\begin{abstract}
How does an early academic, who has specialized training in educational statistics and measurement, approach the teaching of a primary mathematics methods course for first and second year pre-service teachers? The research study presented here explores the design and delivery of a newly developed, singlesemester (36 hours over 9 weeks), course for a combined first and second year pre-service teachers in primary mathematics in a Bachelor of Education (BEd) program. Over the nine week period, the course lecturer and tutorial instructors used action research methodologies to collect and analyze data from the course. Through these data collection and analysis, the authors identified students' common concerns and apprehensions and utilized them as a basis for efforts to enact change for the betterment of the students involved in the class. The collection and analysis of the data as well as the specific actions taken by the authors to these identified concerns and apprehensions are the focus of this paper.
\end{abstract}

Keywords: Action Research; Mathematics Education; Teacher Education

\section{Introduction}

The purpose of this study was to research the impact of the design and delivery of a newly developed, single-semester, course in primary school mathematics in a Bachelor of Education (BEd) program at a university located in a major urban centre on the east coast of Australia. Over a nine week period, we (the authors-who consisted of the course designer and lecturer as well as the tutorial instructors) used as well as modelled an action research approach to this class. By this, we mean that we actively collected and analyzed data gathered from this class in an effort to adjust delivery and better meet the needs of the students. Neither the instructor nor the tutors had ever taught maths methods classes previously. The first author, the course designer and lecturer, holds a $\mathrm{PhD}$ in educational measurement and the second and third authors, the tutorial instructors, hold Graduate Diplomas in Learning and Teaching. On top of this challenging starting position, mathematics is a content area that is typically viewed by pre-service teachers less favorably than their other content classes (Rech, Hartzell \& Stephens, 1993). Lastly, this course represented the combination of both first year and second year pre-service teachers into a single methods class for administrative reasons. This also presented a challenge as although the entire group was early in their respective programs there was a difference between the two groups in terms of experience and growth as pre-service teachers. Taking these three factors into account, it seemed reasonable and worthwhile (as well as necessary) to begin ongoing, systematic data collection and analysis that allowed reflection and adjustment of our teaching to make delivery more effective and impactful for the students. The three authors worked together in concert to actively collect data, comment on the course and course delivery and make necessary changes as the semester progressed.

In this paper we 1) document the data we collected over the course of this nine week semester, 2) discuss how we went about both ongoing and post hoc analysis, 3) suggest ways in which the students may have benefited from seeing and experiencing the action research process and 4) reflect on what we might do to improve our teaching in the future. We describe our experiences of teaching mathematics pedagogy as well as modeling reflective teaching practice to this group of first and second year students. As stated, we employed an action research approach to the exploration and analysis of data in this class. Specifically, we worked under the umbrella of what Ferrance (2000) refers to as "a disciplined inquiry done by a teacher with the intent that the research will inform and change his or her practice in the future." (p. 1). Through the analysis of the class data and our own action research, we have come to recognize some of the common concerns around mathematics and mathematics instruction for beginning teachers which helped to inform our concurrent delivery of the class as well as future iterations. It is our identification of the common concerns and our efforts to address these that will be the focus of this paper.

\section{Theoretical Framework}

In planning our approaches to delivering course content, we were aware that a body of research existed regarding teacher instructional beliefs in mathematics and the influence of those 
beliefs on instructional practice (e.g., Thompson, 2002; Handal, 2003). We also recognized that pre-service teachers have well established and long held attitudes which may be coupled with beliefs about mathematics instruction, beliefs which have developed after spending hundreds of hours in classrooms learning mathematics. Additionally, pre-service teachers might well possess limited conceptual understanding of (Quinn, 2001) and high anxiety and apprehension around (Uusimaki \& Nason, 2004) mathematics. Together, these factors can impact negatively pre-service teachers' beliefs about their ability to teach mathematics and their eventual effectiveness as teachers in this area (Huinker \& Madison, 1997; Quinn, 1997). In light of this potential impact, we were also mindful of the identified need to better prepare pre-service teachers for the realities of their classroom experiences when they begin practicum teaching (Stuart \& Thurlow, 2000). However, it is one thing to be aware of an issue and another thing entirely to address it.

The initial planning for this class which provided the context for our action research was an evolutionary one. There were a wealth of resources available in terms of a standard assigned text (Booker, Bond, Sparrow, \& Swan, 2010), a course outline which was designed and written by the Senior Course Convenor prior to our being assigned this class to teach and which was accepted in its entirety (the three of us were new to this course, institution and content area so acceptance seemed like a wise choice), and a resource and tutorial room stocked with a wealth of math supplies such as manipulatives and games. However, we lacked a clear idea on our path of how to deliver content clearly and effectively and about what exactly one was to do with all these resources. Our main goal was to create a classroom experience that would help reduce students' anxiety around maths and that would help these same students to understand how to apply these resources in their own primary (prep to year 6) maths classrooms. To achieve this goal, we first had to determine how to best use these materials and resources in the typical school classroom and then to apply them to the university one with pre-service teachers. An additional challenge was the actual class sizes (lectures to more than 200 students across two campuses) with numerous tutorials to be planned as well as monitored. In all, the class involved 39 hours of contact time with 26 hours full class lecture and 13 hour long tutorials all over a condensed nine-week semester. On top of this, the first author was unfamiliar with the concept of tutorial at the university level at this point. He had taken lecture and laboratory classes in his undergraduate degree but never had taught within this type of system. It was at this point that the research literature (i.e., English \& Halford, 1995; Grouws, 1992) and other textbooks on mathematics (i.e., Jorgeson \& Dole, 2011; Van de Walle, Karp, \& Bay-Willimas, 2013) proved invaluable to expand our knowledge, confidence and overall direction for this class.

\section{Methods of Inquiry}

To better meet the needs of this class, identify the potential apprehensions these students might be facing and to better prepare them for the realities of teaching, we decided early in the planning stages for this class to take an action research approach to instruction (Ferrance, 2000). We embedded a cyclical design of identifying a problem around these apprehensions (anticipated or recognized), gathering data on that problem, analyzing this data, acting on the data collected (done among the instructor and tutors and explained to the entire class), and ultimately re-evaluating. The course data collection included an instructor and tutor wiki (wikispaces.com), mid-term Classroom Assessment Technique (CAT) (zoomerang.com), and final class evaluations (Blackboard).

The data were interpreted by the instructor and in conjunction with conversations among the tutorial staff, decisions were made as to how best to address the perceived and expressed needs of students. Those decisions typically resulted in the implementation of pedagogical changes, with the results of those changes monitored. For example, assignments quickly emerged as a concern for this group of students so to better explain both the assignment and the accompanying assessment rubric the instructor attended half of all tutorials in the fourth week, providing clarification and answering any questions by the students. Having the instructor complete these sessions, rather than the tutorial instructors provided students with a higher level of consistency across all tutorials. This action was recognized by students as a positive helpful service in both the midterm (i.e., CAT) and final class (i.e., Blackboard) feedback. In an effort to model what we perceive to be good practice in teaching, and to prepare students to undertake similar reflective teaching in their own classrooms, we discussed these steps in our action research and our overall rationale to the students. This was done initially at the beginning of the course, and periodically in lectures as part of ongoing dialogue. For instance, there were feelings of inconsistency between the tutorials as expressed by comments made to tutors as well as emails addressed to the lecturer (e.g., "I attended tutorial this week on Tuesday but found it difficult to learn in the way this tutor teaches and coming from a not so strong mathematics mind I think it's better that I change.”). To address this perception of inconsistency — and avoid an administrative nightmare of students switching tutorials-it was decided that because one of the tutors was already making her own PowerPoint's for tutorials, these PowerPoint's would be extended to all sessions to ensure reliability improved to the benefit of all students. The change was explained to the students as a direct result of their feedback. Data was collected anonymously from the online tool to measure their reaction. It was hoped students could see the process, understand the changes and see that effective sensitive teaching-instead of a linear and pre-set exercise-is an iterative, constantly changing and adjusting practice.

\section{Data Collection and Methods of Interpretation}

As this was a single semester course delivered over the span of nine weeks, the study included data collected over this brief time period. In total there were 317 who were enrolled in this course and who submitted assignments for both tasks. All of the data collected for this study has been done in the context of normal teaching practices and allowed us to consider issues related to the delivery of the course and to students reactions to it. The course data collection included an instructor and tutor wiki, mid-term Classroom Assessment Technique (CAT), and final class evaluations. Throughout the entire semester as well as the research process, all authors strived for open lines of communication and analysis of the class delivery by sharing thoughts, findings and potential strategies with each other as well as with students in a regular and open manner both inside and outside of regular class and tutorial sessions. Engaging in this level of open discussion resulted in the delivery of a more 
consistent class that was responsive and sensitive to the needs of the students that might have otherwise existed.

\section{Wiki}

The class wiki was used as a repository and place for reflection on how the class and the tutorials were unfolding as the semester progressed. It was initially envisioned as a place that all staff could share ideas, issue and concerns and potentially work to some resolution. Although other forms of communication among staff (i.e. texting, phone, emails and face-to-face conversations) replaced some of the purpose of the wiki, some useful and potentially beneficial comments and themes did emerge from it. For example, 1) engagement and attendance was identified as positive (e.g., "Most of the students were engaged”); 2) that the first and second year classes responded differently (e.g., "There is a growing difference between the first and second years in terms of engagement”, "There was a significant difference in understanding between the first and second years"); 3) how to teach maths; 4) that students did not want as much theory in tutorial but more application (e.g., "Encourage students to have a go at teaching some of the examples”); and, 5) how ACARA (Australian Curriculum) and the QSA (Queensland Curriculum) needs to be brought into the content coverage and linked for their understanding.

\section{Classroom Assessment Techniques}

Classroom Assessment Techniques are formative evaluation methods that serve two purposes. They can help instructors to assess the degree to which students understand the course content and they can provide information about the effectiveness of teaching methods (Haugen, 1999). Most are designed to be quick and easy to use and each CAT provides different kinds of information. This CAT was administered in the fourth week of the course and was placed on-line via zoomerang.com and a link was sent out to the entire class. A week was given for students to respond to three prompts 1) So far in the course I am most satisfied with? 2) So far in the course I am most least satisfied with; and, 3) So far in the course I am having trouble with.

All responses were downloaded anonymously and coded by theme. Approximately a third of the class responded to the CAT and results from the three prompts are provided below in Tables 1-3.

Table 1 offers an overview of what had been working well in the class to this point. Almost $75 \%$ of respondents indicated that lecture, the critical reflection upon pedagogical content and the overall learning environment were working to their satisfaction. Examples of comments from these areas of satisfaction include 1) "The lecturer and the lectures-the delivery is engaging an interesting"; 2) "the critical way your address the textbook and provide alternative ideas"; and, 3) "the learning environment that lowers the stress level by $10 \%$-if you can measure stress level?"

Table 2 offers an overview of what had up to that point in the class not been working well. Over $80 \%$ of respondents indicated that they were not satisfied with four areas: the tutorial, the class structure, nothing and lectures. Examples of comments from these areas of dissatisfaction include 1) "I feel the tutorials need to include more content” and "I feel I am not getting anything from tutorials"; 2) "dislike double lectures and tutorials in a week"; and, 3) "the lectures seems to go on forever!"
Table 1.

Student response to initial classroom assessment technique to question "So far in the course I am most satisfied with?"

\begin{tabular}{ccccc}
\hline Code & Value & Description & $\begin{array}{c}\text { Number of } \\
\text { Responses }\end{array}$ & $\begin{array}{c}\text { Percentage of } \\
\text { Responses }\end{array}$ \\
\hline 1 & L & Lectures & 56 & 43.75 \\
2 & CR/C & $\begin{array}{c}\text { Critical } \\
\text { Reflection/Content }\end{array}$ & 24 & 18.75 \\
3 & LE & Learning Environment & 18 & 14.1 \\
4 & T & Tutorial & 9 & 7 \\
5 & AD & Assignment Details & 8 & 6.25 \\
6 & V & Videos & 5 & 3.9 \\
7 & L@G & Webboard Discussions & 3 & 2.3 \\
8 & $\mathrm{~S}$ & Surveys & 1 & .8 \\
9 & Nt & Notes & 1 & .8 \\
10 & M & Misc. & 3 & 2.3 \\
Total & & & 128 & 99.9 \\
\hline
\end{tabular}

Table 2.

Student response to initial classroom assessment technique to question "So far in the course I am least satisfied with?"

\begin{tabular}{ccccc}
\hline Code & Value & Description & $\begin{array}{c}\text { Number of } \\
\text { Responses }\end{array}$ & $\begin{array}{c}\text { Percentage of } \\
\text { Responses }\end{array}$ \\
\hline 1 & T & Tutorial & 37 & 39.4 \\
2 & CS/A & Class Structure/Admin & 20 & 21.2 \\
3 & N & Nothing & 13 & 13.8 \\
4 & L & Lectures & 12 & 12.7 \\
5 & TA & Talking & 6 & 6.4 \\
6 & MC & Maths Content-Maths Is & 3 & 3.2 \\
7 & AS & Hard & 2 & 2.1 \\
8 & G & Gsignment Structure & 1 & 1.1 \\
Total & & & 94 & 99.9 \\
\hline
\end{tabular}

Table 3.

Student response to initial classroom assessment technique to question "So far in the course I am having trouble with?"

\begin{tabular}{ccccc}
\hline Code & Value & Description & $\begin{array}{c}\text { Number of } \\
\text { Responses }\end{array}$ & $\begin{array}{c}\text { Percentage of } \\
\text { Responses }\end{array}$ \\
\hline 1 & N & Nothing & 32 & 33.8 \\
2 & L & Lecture & 17 & 17.5 \\
3 & C & Content & 16 & 16.4 \\
4 & T & Tutorial & 12 & 12.3 \\
5 & AS & Assignment & 7 & 7.2 \\
6 & R & Readings & 5 & 5.2 \\
7 & TA & Talking Students & 4 & 4 \\
8 & M & Motivation & 4 & 4 \\
Total & & & 128 & 99.95 \\
\hline
\end{tabular}

Lastly, Table 3 offers student comments on what they were having trouble with. Almost $35 \%$ of respondents indicated 
nothing and another $45 \%$ indicated lecture, content and tutorial. Examples of these identified difficulties included 1) "The lectures go too fast”; 2) "taking in and absorbing all the information"; and, 3) "the tutorials seem like a waste of time".

\section{Final Evaluations}

As part of the University policy, all classes (lecture and tutorials) are to be evaluated at the end of term via an online survey format similar to the CAT done previously for this class. Although the questions were slightly different, they did capture some of the same aspect of the class. As with the CAT, all responses were downloaded anonymously and coded by theme. Again, approximately a third of the class responded to this survey and results from the two prompts are provided below in Tables 4 and 5. Table 1 offers an overview of students' attitudes at the completion of the lecture and tutorials.

Table 4 offers students a second opportunity to comment on what was good about this course. Almost $90 \%$ of respondents indicated that lecture, the tutorials, the support from staff and the content were good. Examples of comments from these areas of satisfaction include 1) "The lecturer was excellent and the tutors were there to help you learn"; 2) "During tutorials we were able to get involved in experiences by actually teaching"; and, 3) "I was hoping for more maths than how to teach maths."

Table 5 offers an overview of the feedback from students on how the class could be improved in the future. In this case, 95\% of respondents indicated that tutorials, the assessments and the content (along with nothing) could be improved for future iterations of the class. Examples of comments from these areas include 1) "Tutors seemed unsure at times, which lead to confusion and contradictions to lectures"; 2) "The assessment tasks could have been worded better and more specific"; and, 3) "The layout of the course as to what was taught was in a weird pattern.”

\section{Common Themes (Key Responses to Action Research)}

Early on in the delivery of this class (primarily from data via tutorial instructors through the wiki and conversations and supported through the initial CAT) it became apparent that there was a substantial amount of student concern around the usefulness of tutorials, the value of teaching maths pedagogy over maths content and the general approach and delivery of the lecturer. From an action perspective, these were positive as they allowed for potential adjustments (i.e., either offering a better rational for the approach to pedagogy or in simply talking slower in lecture) based upon this feedback, Additionally, they also offered a demonstration for student on how these are being made as well as an opportunity to measure near the end of the class on how these were received.

Initial responses to the tutorial. During the first series of lectures and tutorials, it became apparent both through our contact with the students as well as through our internal conversations (informally and via the wiki) that there was some concern with the delivery of the tutorial. For example, at the initial CAT only $7 \%$ of students responded that the tutorial was the most satisfying aspect of the class while almost $40 \%$ indicated that it was the most dissatisfying. Based upon this feedback and our own conversations, the tutorials were adjusted and expanded to include more application as well as student teaching. In support for this adjustment, there was a discernible change in the tuto-
Table 4.

Student response to final class evaluations to question "What was good about this course?”

\begin{tabular}{ccccc}
\hline Code & Value & Description & $\begin{array}{c}\text { Number of } \\
\text { Responses }\end{array}$ & $\begin{array}{c}\text { Percentage of } \\
\text { Responses }\end{array}$ \\
\hline 1 & L & Lectures & 62 & 57.4 \\
2 & $\mathrm{~T}$ & Tutorials & 14 & 12.8 \\
3 & $\mathrm{SS}$ & Supportive Staff & 11 & 10.1 \\
4 & $\mathrm{C}$ & Content & 10 & 9.3 \\
5 & $\mathrm{~V}$ & Videos & 2 & 2 \\
6 & $\mathrm{M}$ & Materials & 1 & 1 \\
7 & $\mathrm{~T}$ & Text & 1 & 1 \\
Total & & & 108 & 100 \\
\hline
\end{tabular}

Table 5.

Student response to final class evaluations to question "How could this course be improved?”

\begin{tabular}{ccccc}
\hline Code & Value & Description & $\begin{array}{c}\text { Number of } \\
\text { Responses }\end{array}$ & $\begin{array}{c}\text { Percentage of } \\
\text { Responses }\end{array}$ \\
\hline 1 & T & Tutorials & 34 & 43 \\
2 & AS & Assessment & 15 & 19 \\
3 & C & Content & 14 & 17.7 \\
4 & NA & Nothing & 13 & 16.5 \\
5 & M & Mixture and Atmosphere & 3 & 3.7 \\
Total & & & 79 & 99.9 \\
\hline
\end{tabular}

rial ranking as a positive or worthwhile learning experience from $7 \%$ initially to almost $13 \%$ at course conclusion.

Content vs. pedagogy. There has been a long running dilemma among mathematics educators of how to teach mathematics (i.e. how much time should be devoted to teaching actual maths and how much to strategies for teaching these concepts) (Gurganus, 2007). We had thought about how to approach this class from the very beginning and although there was some concern among the students about their lack of content knowledge throughout the delivery, we were encouraged that close to $60 \%$ of respondents indicated that lecture and content were working to their satisfaction at both points in the feedback cycle. This was perhaps best articulated by one student who commented that "I feel I gain valuable information of attending (lectures) and find I am able to walk away from them questioning past teaching methods and starting to form new more effectives ones that are my own.”

\section{Educational Significance}

We began this process with the task of presenting an educational methods class in mathematics to a group of pre-service teachers early in their teaching development. Recognising many of these students would approach mathematics with some degree of reticence if not outright anxiety and consternation, we sought to find a way to offer a meaningful and worthwhile learning experience while simultaneously modelling reflective practice and allow students to offer feedback and adjust the direction of the class to better meet their learning needs. Overall, we identified the amount of content that was covered, the long lecture format and the ways that tutorials were structured and the as common concerns and apprehensions among the 
students.

We also hoped that this would model good pedagogy for these students and allow them to leave with new ideas and approaches to teaching primary mathematics as well as general approaches to their own current and future classroom behaviour. To this end we hope and believe we were successful on both fronts. The data demonstrated that students would offer feedback on how to adjust the course delivery and would respond to these changes and that despite some concern with their own content knowledge in this area students were able to recognise some learning in terms of how they might go about teaching this content area in their own classes. However, this research also reflects how complex trying to measure the delivery of a class such as this is and how difficult it is to measure if we have or have not been effective.

We continue to ask questions of our own actions: Could more informal data collection have improved our delivery? Would background knowledge of students be something to collect at the onset to guide our instruction? Should students be required to do more content classes prior to methods classes? With the help of our students we can continue to ask such questions and to uncover more learning.

\section{Limitations}

The major limitation concerning this study relates to the responses rates of the Classroom Assessment Techniques (CATs). Although the authors were happy with the overall response rates (approximately 35\%), there is some concern that this 35\% response rate captures the same students for both sessions. These students may have been a biased group who were motivated to respond for specific reasons and who might have not been representative of the entire class.

\section{REFERENCES}

Booker, G., Bond, D., Sparrow, L., \& Swan, P. (2010). Teaching primary mathematics (4th ed.). Malaysia: Pearson.

English, L. D., \& Halford, G. S. (1995). Mathematics education: Mo- dels and processes. Mahawah, NJ: Lawrence Erlbaum Associates.

Ferrance, E. (2000). Themes in education: Action research. Providence, RI: Northeast and Islands Regional Educational Laboratory. www.lab.brown.edu.

Grouws, D. A. (1992). Handbook of research on mathematics teaching and learning. New York: Macmillian.

Gurganus, S. P. (2007). Math instruction for students with learning problems. Sydney: Pearson.

Handal, B. (2003). Teacher's mathematical beliefs: A review. The Mathematics Educator, 15, 47-57.

Haugen, L. (1999). Classroom assessment techniques. http://www.celt.iastate.edu/teaching/cat.html

Huinker, D., \& Madison, S. K. (1997). Preparing efficacious elementary teachers in science and mathematics: The influence of methods courses. Journal of Science Teacher Education, 8, 107-126. http://dx.doi.org/10.1023/A:1009466323843

Jorgeson, R., \& Dole, S. (2011). Teaching mathematics in primary school (2nd ed.). Crows Nest, NSW: Allen \& Unwin.

Quinn, R. J. (1997). Effects of mathematics methods courses on the mathematical attitudes and content knowledge of pre-service teachers. Journal of Educational Research, 91, 108-113. http://dx.doi.org/10.1080/00220679709597528

Rech, J., Hartzell, J., \& Stephens, L. (1993). Comparisons of mathematical competencies and attitudes of elementary education majors with established norms of a general college population. School Science and Mathematics, 93, 141-145. http://dx.doi.org/10.1111/j.1949-8594.1993.tb12212.x

Sturat, C., \& Thurlow, D. (2000). Making it their own: Pre-service teachers' experiences, beliefs, and classroom practices. Journal of Teacher Education, 51, 113-121. http://dx.doi.org/10.1177/002248710005100205

Thompson, A. G. (1992). Teachers' beliefs and conceptions: A synthesis of the research. In D. A. Grouws (Ed.), Handbook of research on mathematics teaching and learning (pp. 127-146). New York: Macmillian.

Uusimaki, L., \& Nason, R. (2004). Causes underlying pre-service teachers' negative beliefs and anxieties about mathematics. Proceedings of the 28th Conference of the International Group for the Psychology of Mathematics Education, 4, 369-376.

Van de Walle, J. A., Karp, K. S., \& Bay-Williams, J. M. (2013). Elementary and middle school mathematics: Teaching developmentally (8th ed.). Upper Saddle River, NJ: Pearson. 